\title{
APORTE DE LA ARQUEOLOGIA URBANA A LA CONSERUACIÓN DEL PATRIMONIO ARQUITECTÓNICO Y URBANO DE LA CIUDAD DE CORRIENTES
}

\section{Patricia MARIÑO}

Patricia Mariño. Jefa de Trabajos Prácticos. Cátedra Conservación del Patrimonio Arquitectónico y Urbano. Facultad de Arquitectura y Urbanismo, UNNE.Email: pmarinio@yahoo.es

Palabras Clave: Conservación, arqueología urbana.

Keywords: Conservation, urban archaeology.

\section{RESUMEN}

La consideración de la ciudad y su arquitectura como testimonios del pasado, en tanto punto de convergencia entre historia, sociedad y tecnología, fundamentos de futuras intervenciones y planificaciones, implica el abordaje de estas acciones desde el punto de vista de la conservación del patrimonio arquitectónico y urbano, y la inclusión de la arqueología urbana.

Se abordan experiencias de manejo del patrimonio urbano correntino en relación con la arqueología urbana, y su potencial en la planificación de tareas de conservación arquitectónica y urbana, lo que requiere una reflexión de acuerdo con los criterios de conservación actuales

\section{ABSTRACT}

The consideration of the city and its architecture as testimonies of the past, while point of convergence between history, society and technology, foundations of future interventions and planning, implies the boarding of these actions from the point of view of the conservation of the architectural and urban heritage, and the incorporation of the urban archeology. Experiences of urban heritage management of the city of Corrientes, in relation to urban archeology and its potential in planning tasks architectural and urban conservation, requires consideration of the criteria according to current conservation. 
"la conservación del patrimonio cultural debe ser una parte integral de los procesos de planificación y gestión de una comunidad y puede contribuir al desarrollo de esta comunidad".

\section{OBJETIVO}

Reconocer el valor de la arqueología urbana en las obras de conservación emprendidas en la ciudad de Corrientes, determinando su potencial para el conocimiento de la arquitectura y el desarrollo de la comunidad.

\section{INTRODUCCIÓN Y PLANTEO}

Hace aproximadamente cuarenta años, la renovación de los centros históricos europeos y la ampliación de la noción de patrimonio y el mejoramiento de las técnicas de estudio contribuyeron a la reconsideración arqueológica de las ciudades (TUNA, 1999). Entendida como una arqueología de lo urbano, actualmente también los objetos urbanos han sido incluidos y registrados con precisión según el interés particular de las prospecciones (COULOMB, 2012).

La Carta de Cracovia (UNESCO, 2000) establece que "la conservación del patrimonio cultural debe ser una parte integral de los procesos de planificación y gestión de una comunidad y puede contribuir al desarrollo de esta comunidad". Por ende, el proyecto de intervención debe realizarse con una concepción unitaria que integre conocimientos previos, acciones posibles y estrategias de seguimiento.

El logro de una acción sistemática, de aproximación al conocimiento profundo de los bienes culturales a través de la arqueología urbana, surge de la aplicación de los métodos de gestión, de determinación de planes con carácter vinculante y definición de prioridades. Estos deben abarcar no solo la previsión de los mecanismos financieros que incluyan a las excavaciones, sino también las intervenciones de restauración, de conservación y puesta en valor para su aprovechamiento como recurso turístico.
En las fases de la implementación de la gestión, la educación se convierte en una estrategia. La educación rescata una imagen que el tiempo empezó a desdibujar y se propone conservarla y transmitirla.

\section{ANTECEDENTES}

La arqueología ha devenido un saber sobre el futuro del pasado urbano, y por lo tanto, considerada necesaria en la formación de cuadros municipales. La creación de la Escuela de Altos Estudios Urbanos por el Consejo General del Sena, en 1919, responde a la ambición de enseñar la ciencia comunal.

La toma de conciencia sobre el patrimonio urbano y el potencial del suelo urbano es una consecuencia de la Segunda Guerra Mundial, cuando a causa de la masiva destrucción se deben reconstruir numerosos edificios y se revelan estratificaciones de gran espesor trasluciendo formas de la antigüedad.

Si bien la arqueología urbana se origina específicamente con esa denominación en los años 90, en la Argentina existen casos anteriores, de los años 80 , como el de la excavación del Caserón de Rosas, dirigida por el Dr. Arq. Daniel Schavelzon y secundada por el Mgter. Arq. Jorge Ramos.

En 1986, los arquitectos Schavelzon y Ramos organizaron la investigación del Caserón de Rosas, cuyo objetivo fue verificar no solo su proceso de construcción, sino también el espacio sobre el que se fundó, para descubrir vestigios de otras edificaciones anteriores. A diferencia de otros trabajos, en los cuales se intentaba hacer arqueología del edificio, aquí se investigó el devenir histórico del suelo urbano (SCHAVELZON y RAMOS, 2006). Esta investigación se gestionó desde la Universidad de Buenos Aires, y obtuvo luego de dos años el apoyo del Banco Ciudad de Buenos Aires, la Fundación Antorchas y otras instituciones privadas. 
Algunas investigaciones arqueológicas, relacionadas con trabajos de restauración, se han iniciado en la ciudad de Corrientes, como el proyecto de Casa Molinas o Casa Martínez. Estas edificaciones son de gran importancia en la ciudad, por ser testimonios de la arquitectura colonial residencial desarrollada en el área guaranítica, en dos períodos bien diferenciados: siglo XVII e inicios del siglo XIX. Además, cabe destacar que Casa Martínez es un ejemplo de la evolución de la tipología residencial desde el período colonial al liberal.

Casa Molinas, ejemplo de la arquitectura colonial a inicios del siglo XIX, constituye un rescate arqueológico de 1996, realizado en la medida de las circunstancias técnicas, legales y administrativas, y cuya comunicación ha sido parcial. Debería presentarse in situ un soporte comunicativo que permita comprender la evolución constructivo-espacial del edificio, así como también los elementos rescatados que contribuyen a su explicitación.

La intervención de Casa Martínez (Monumento Histórico Nacional) iniciada en 2009, que incluyó una excavación arqueológica emprendida por el licenciado Juan Ignacio Mujica, autor del trabajo de prospección de Casa Molinas, lamentablemente debió interrumpirse por cuestiones económicas. Esta circunstancia dejó los vestigios constructivos sometidos a un mayor deterioro, motivado por el abandono de las excavaciones realizadas, lo que devela la precariedad de las normativas existentes y de la gestión del patrimonio arqueológico.

Se observa un continuo crecimiento de las obras nuevas, no solo en el centro histórico de la ciudad de Corrientes, sino en zonas que conformaban los distintos anillos funcionales de sus etapas, colonial y republicana, coincidentes con otros equipamientos de importancia en la conformación de las funciones urbanas.
La inclusión del interés arqueológico, entre los objetivos del Instituto de Cultura de la Provincia de Corrientes, creado en el año 2010, constituye un avance en la consideración de la arqueología urbana, aunque aún sin articulación con las acciones del municipio capitalino, que requiere un registro y el análisis de los vestigios del pasado urbano, frente al avance de nuevas obras.

Como antecedentes del aporte de la arqueología a la conservación edilicia, es útil mencionar la iglesia del Salvador de Sevilla, la segunda más grande después de la catedral de la misma ciudad, sometida a trabajos de construcción iniciados en 1674 con el arquitecto Esteban García y acabados en 1712 con Leonardo De Figueroa. Se erige sobre los restos de la Mezquita Mayor, que en sus orígenes era la principal mezquita de Sevilla, de origen árabe en el siglo IX, de la que resta el Patio de Abluciones y la base de su torre.

A lo largo de dieciséis años, apoyada en tres proyectos de restauración y otros tres de emergencia, se desarrollaron labores imprescindibles de restauración y conservación en la antigua Colegial de El Salvador.

Parte del trabajo de restauración integral del templo del Salvador consistió en la excavación arqueológica, realizada como apoyo a la restauración y complemento del proceso de intervención. Participó en el control del movimiento de tierras necesario para la eliminación de humedades y recalce de la cimentación, así como con actuaciones específicas para detección de los restos de la mezquita de Addabbás (SOLÍS BURGOS, 2004).

La recolección de datos generales en el proceso de restauración ayudó a la interpretación histórica, tecnológica, formal y funcional del proceso edificatorio desde su materialidad. El conocimiento del edificio islámico se incrementó con el aprovecha- 
miento de las obras de restauración, en combinación con el desarrollo de pequeñas actuaciones autónomas de reconocimiento de partes del edificio para su correcta valoración científica y cultural.

La excavación controlada del relleno existente hasta el pavimento de la Colegial medieval permitió un control arqueológico preciso, con recuperación de los materiales de interés y el conocimiento completo de la antigua mezquita.

\section{RESULTADOS}

Nuestro caso de estudio, la ciudad de Corrientes, desde el siglo XIX ha sido objeto de diversos, aunque escasos, estudios arqueológicos, mayoritariamente orientados a un interés antropológico.

Resulta llamativo observar que los inicios de los estudios arqueológicos referidos al patrimonio urbano correntino fueron concretados por estudiosos no especializados en el área. En 1857 se aprecia la presencia de Fr. J. Nepomuceno Alegre O. Fm. y el Dr. Amado Bonpland (CÓRDOBA, 1934); tiempo después, con un objeto diferente por el profesor Ambrosetti, todos ellos estudiosos, aunque no especialistas en la disciplina.

A fines del siglo $X X$, se observa el interés por la arqueología urbana correntina. En 1994, gracias a la colaboración profesional del licenciado en Arqueología Juan Ignacio Mujica, en la restauración de la casa Molinas, ubicada en el centro histórico de la ciudad de Corrientes.

Una intervención para el estudio de la historia material del origen de la ciudad de Corrientes se desarrolla gracias al interés del fraile franciscano Alegre, secundado por el Dr. Bonpland como perito oficial, para investigar la ubicación del fuerte fundacional en la punta Arazaty, cuando descubren una construcción de piedras areniscas y restos de empalizada (GÓMEZ, 1942).
Escasas intervenciones urbanas y edilicias de la ciudad de Corrientes, tanto para obras nuevas como de conservación, incluyen dentro de la etapa de diagnóstico de su planificación la prospección arqueológica. También se denota la ausencia de previsión de la circunstancial integración y articulación de un equipo de investigación en el proceso de la obra.

A diferencia de la realidad de la planificación arquitectónica y urbana correntina, vemos en el interior de la provincia de Corrientes, en casos como el de San Carlos, o especialmente el de La Cruz, la fuerte presencia de la arqueología urbana, cristalizada en rescates que ponen en valor el patrimonio arquitectónico, como soporte de la historia de las Misiones Jesuíticas.

La comunidad correntina inicia un proceso de conciencia sobre su patrimonio arqueológico, a través del reclamo sobre los bienes que conforman el soporte de su identidad, en algunos casos señalados a través de iniciativas civiles. Estas se promueven desde ONG que a partir del auge de las redes sociales difunden el valor de la memoria urbana y la importancia de la arqueología como instrumento para su conocimiento.

Actualmente, existe el proyecto de Ley "Arqueólogo de la Provincia", promovido por el senador Gustavo A. Canteros, tendiente a definir la acción del profesional, para resguardar y proteger el patrimonio arqueológico de la provincia, como complemento de los objetivos que intenta desarrollar la Ley de Creación del Instituto de Cultura de la provincia de Corrientes del año 2010.

Distintos edificios de valor patrimonial de la ciudad de Corrientes, como así también diversas áreas urbanas, merecen un estudio arqueológico, a fin de conocer fragmentos de nuestro proceso de evolución urbano.

Se toman como muestra algunos ejemplos del patrimonio religioso correntino, sometidos a proyectos de intervención, algunos concretos y otros 
...intervenciones sin una perspectiva integral que logre una recuperación de los valores simbólicos perdidos y considere etapas anteriores de su proceso constructivo".

en proceso de gestión, en los que la investigación arqueológica es una variable obligada para comprender el carácter simbólico de las modificaciones espaciales dadas a través del tiempo.

En las últimas intervenciones realizadas en el templo de La Cruz de los Milagros, se observa la ausencia de criterios de conservación vinculados con las últimas normativas internacionales de preservación del patrimonio arquitectónico y con la legislación existente, especialmente con la arqueología urbana. Ello se traduce en intervenciones sin una perspectiva integral que logre una recuperación de los valores simbólicos perdidos y considere etapas anteriores de su proceso constructivo.

Cabe recordar que el templo de la Cruz se sitúa en un sector donde existieron dos templos anteriores al actual y donde funcionó el primer cementerio municipal en 1828, además de utilizarse como cementerio desde la creación de la parroquia en el siglo XVII.

La presencia de los religiosos en torno al enfermo y difunto, el expendio de los últimos sacramentos, la ceremonia religiosa en el templo son los signos de la buena muerte, garantía de una resurrección triunfante, según lo instituye la Iglesia Cristiana desde el siglo XII (DEREGNACOURT, 2007). Esta tradición, unida a la de los enterramientos en el interior y el exterior de los templos, es una constante en la historia de nuestros templos, que renace cíclicamente.

Reservadas a una cierta elite, las sepulturas ubicadas bajo las iglesias constituyen una fuente de ingresos considerable para su construcción, aunque no está exenta de inconvenientes. Implica desplazar bancos, caer bajo las lápidas, generar malos olores según la profundidad y características del suelo. En el siglo XIX, este hábito fue prohibido, pero pese a ello muchos civiles solicitan ser enterrados en terrenos de los templos.

El Conjunto Franciscano aún posee vestigios de enterramientos en el antiguo sector de quintas y huertos (hoy sector de alquiler), en su convento, o bien en el templo San Francisco Solano. Bajo el sector de contrasacristía o altares del Sagrado Corazón de Jesús, distintos objetos son indicadores de los ritos funerarios que giran en torno al templo, ya que se puede observar la presencia de lápidas en muros de la nave lateral izquierda, un catafalco en sacristía, y se hallaron restos óseos humanos durante cateos de suelos. Se encontraron a $2.00 \mathrm{~m}$ de profundidad en nave lateral izquierda, a 1.60 $m$ en contrasacristía y en exterior de nave lateral derecha, cercana al baptisterio.

Uno de los sectores del conjunto franciscano, el denominado rentado, presenta una cisterna rescatada, ubicada en la misma línea del aljibe situada en el centro del claustro principal, lo cual es lógico para la función de ser reservorio de agua. Al estar situado en un nivel menor a un metro con sesenta centímetros, el desnivel sirve para dar pendiente y llegar a llenar la cisterna.

Se descubrió la cisterna debido a la existencia de una pared derrumbada y con una visible fisura a $45^{\circ}$, del tipo de las que se producen por asentamiento de suelo. También se destacaba, contigua a esta, una depresión en el suelo que tomaba una forma circular.

Dentro del relleno de la cisterna se encontró gran cantidad de fragmentos de vajilla (copas de vidrio, tasas y platos de loza), cubiertos, botellas de vino, botellas de agua mineral Villavicencio de la década del 50, botellas de perfume, frascos de gomina, planchuelas de hierro perforado, una bala de cañón, que probablemente haya llegado a la cisterna con el relleno de tierra del convento, ya que esta contenía elementos similares a los encontrados debajo del sitio donde se construyó la rampa situada a diez metros (MARIÑO, 2007: 336).

Al realizarse las excavaciones para recalce de cimientos, se encontraron también herraduras, herrajes coloniales, algunos restos óseos de animales, que permitieron enriquecer la comprensión del tipo de actividades que se realizaban en este sector, de las que solo existen algunos datos incompletos. 
1. Patrimonio Urbano arquitectónico del Orden de los Frailes Menores. Ficha de edificios. Fuente: Convento san francisco de Asís. Corrientes.

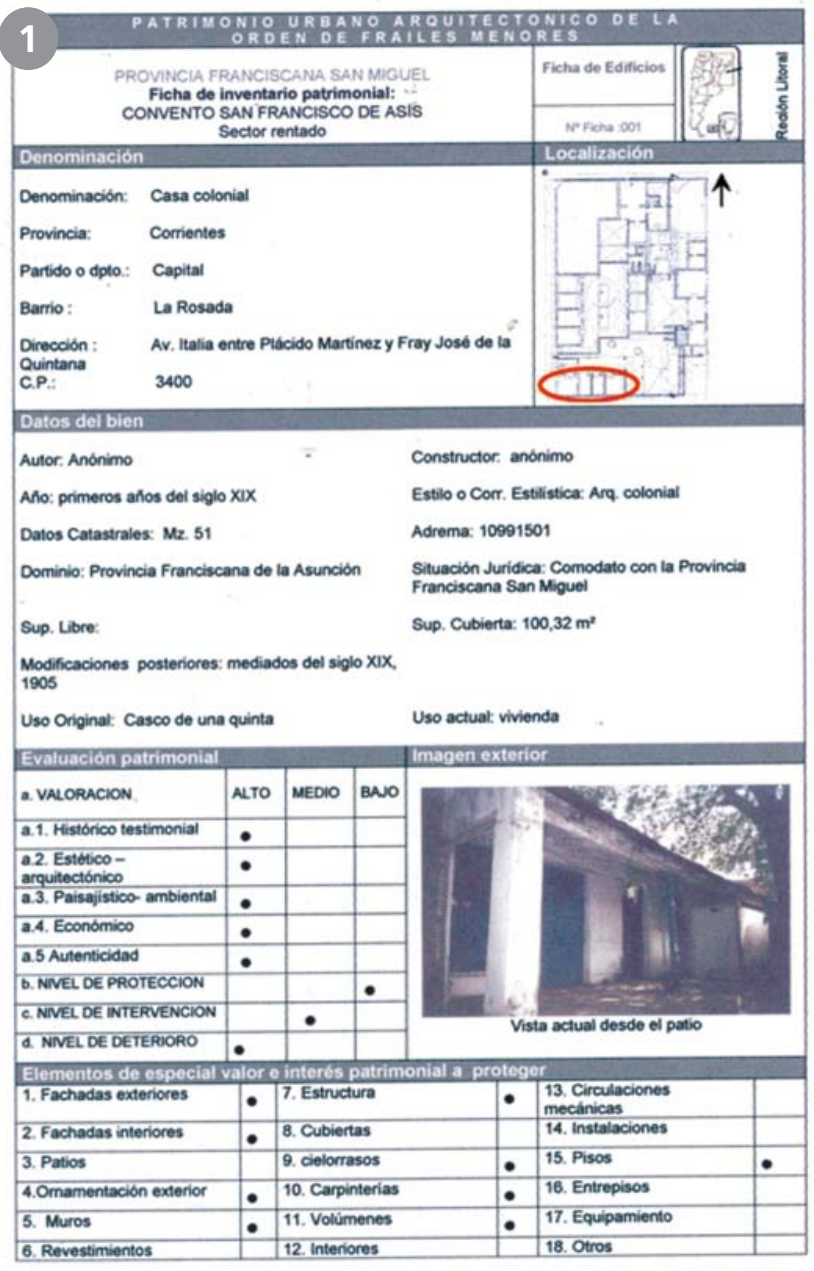

Distintos componentes constructivos fueron rescatados en la intervención que se realizó entre los años 2005 a 2006, algunos con el objeto de ser restaurados, reutilizados o reemplazados por otros. Tirantes y dinteles de distintas maderas, carpinterías de pinotea de fines de siglo XIX, baldosas y tejas Pierre Sacoman, veldosas coloniales del siglo XVIII. En la ejecución de la obra, se descubrió un antiguo solado de ladrillo de $0,18 \times 0,36 \mathrm{~m}$, asentado sobre tierra apisonada debajo de los solados de todas las habitaciones de la construcción N. ${ }^{\circ} 2$ (ver ficha de inventario). Este probablemente haya sido el solado del patio de servicio de los antiguos moradores de la vivienda o bien el solado del área que ocuparon los sirvientes y esclavos del convento. ${ }^{1}$

La excavación de la cisterna puso al descubierto un solado de antiguas veldosas* coloniales de 0,14 $\mathrm{m} \times 0,14 \mathrm{~m}$, similar al encontrado debajo del contrapiso del convento, por lo que es muy probable que el relleno de la cisterna se haya realizado en

[1 ] ARCHIVO GENERAL DE LA NACIÓN. Fondo Corrientes. HACIENDA. LEGAJO N.․ 17. Nota al Teniente General. Fr. Miguel -Sánchez Moreno, Fr. Bartholomé de Valenzuela, Fr. Juan José del Águila y Ríos, Fr. Antonio Cabrera. 22 de mayo de 1760.

${ }^{*}$ ] Veldosas es el término con el que se señalan las piezas de barro cocido, utilizadas como solado.

Tomado de MORENO, CARLOS (1995) De las viejas tapias y ladrillos. T. 4. ICOMOS, Agencia El Cid, Diario El Viajero, Bs. As.

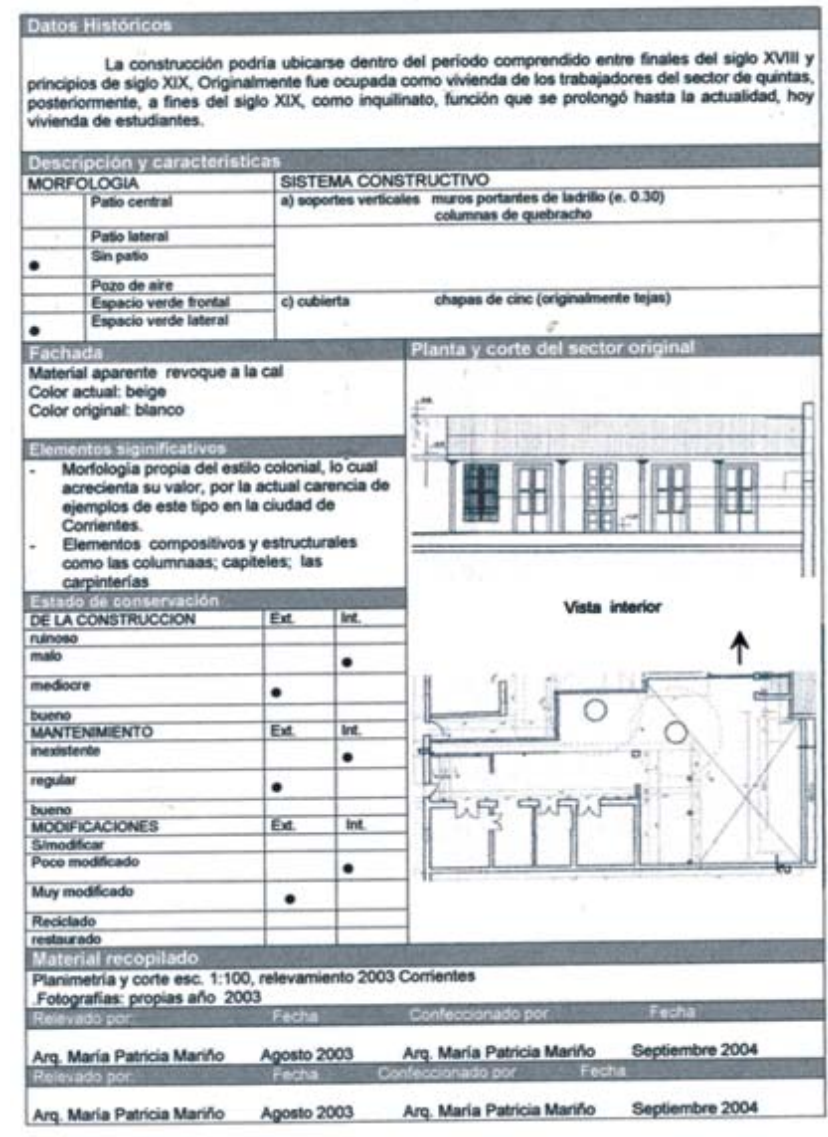

el mismo período de la restauración del convento. Las veldosas fueron removidas y guardadas, al igual que las de las habitaciones del antiguo hotel La Sirena, construcción colonial que en un sector tenía solado de ladrillos y en el otro, estas mismas veldosas (MARIÑO, 2007: 337).

Testimonio del manejo de ciertos recursos tecnológicos y económicos, los componentes constructivos rescatados dan cuenta además del uso de los distintos espacios del conjunto franciscano. A partir de estas experiencias y el conocimiento de la evolución histórica de la ocupación del suelo correntino, en un informe para la conservación del templo San Francisco Solano, de mayo de $2011^{2}$ (ACSF, 2011), que la autora recomendó en calidad de miembro de la Comisión Pro-Templo, se solicitó a los proyectistas (Dirección Provincial de Arquitectura de Corrientes) se gestionara por otra vía la realización de cateos arqueológicos.

Cobraron fundamental fuerza como fundamentos los vestigios surgidos en los estudios del Dr. Ing. Nello D'ascenzo en 2005, como así también en las intervenciones que la misma autora dirigiera en el sector rentado de la manzana franciscana (MARIÑO, 2006). 
un hallazgo trascendental fruto de las excavaciones realizadas desde 2010, en el sitio del templo jesuítico guarani de La Cruz".

Hasta la actualidad, continúan las gestiones para la restauración del templo San Francisco Solano, lo que se comunica en distintos diarios locales. En algunos incluso se cita la iniciación de los trabajos de consolidación de las fundaciones; sin embargo, permanecen ausentes todo tipo de investigaciones arqueológicas en el sitio. La plaza Cabral, en su intervención del año 2012, también incorporó el estudio de una antropóloga, dado el hallazgo de un gran pozo construido con mampostería de ladrillos durante la intervención del espacio, acción gestionada entre el Municipio y el Centro de Estudios Históricos de Arquitectura y Urbanismo (CEHAU) de esta universidad.

El interior de la provincia de Corrientes muestra algunos ejemplos de la concreción de proyectos de arqueología urbana, como el de la antigua reducción jesuítica de La Cruz, donde se implementó sistemáticamente un programa de acciones gestionado por el Municipio de La Cruz desde el año 2006, en el marco de una política institucional destinada a la recuperación del patrimonio histórico.

A partir del rescate posibilitado por trabajos de arqueología urbana, desarrollados por el Equipo de Arqueología Municipal que dirigió la Lic. María Eugenia Turus, se concretó la obra de puesta en valor de los Hornos Jesuíticos de Tejas y Ladrillos (2007), se reestructuró el Museo Parroquial Ramón Félix Mansilla (2008), se creó el Centro de Atención al Turista con una sala de interpretación histórica (2009) y se restauraron y pusieron en valor muros del casco histórico (2010).

En una entrevista realizada en 2010 a la licenciada Turus, la autora pudo rescatar la experiencia dada en trabajos de arqueología emprendidos gracias a la gestión permanente del municipio, ante instituciones estatales provinciales, nacionales e internacionales. Se trabajó en forma conjunta con la Asociación Española de Cooperación Internacional, la
Fundación Naturaleza para el Futuro (FUNAFU) y la Dirección Provincial de Relaciones Internacionales para el rediseño de cartelería turística y creación del Centro de Interpretación de las Misiones Jesuíticas Guaraníes de Corrientes Ñembyaty (2010).

Actualmente puede apreciarse un hallazgo trascendental fruto de las excavaciones realizadas desde 2010, en el sitio del templo jesuítico guaraní de La Cruz. No solo se encontraron los primeros indicios materiales de la iglesia del siglo XVIII, sino que se registró debajo de sus restos el sorprendente hallazgo de enterratorios humanos, también jesuíticos, aunque anteriores a la construcción del templo, y evidencias de la quema del templo de la reducción, producida en 1817 como consecuencia de la invasión portuguesa. Se registraron elementos rescatados en la excavación como fragmentos de veldosas octogonales, una base de columna de piedra y posibles vestigios del púlpito. Todos estaban cubiertos por una capa de escombros de tejas, restos carbonizados de madera y caña y clavos forjados que indican el derrumbe del techo.

Bajo el nivel de piso del templo, luego de profundizar sobre un sector donde las veldosas fueron removidas por anteriores intervenciones, se descubrieron diecinueve fosas funerarias ubicadas en sentido norte-sur, que formaron parte de uno de los primeros cementerios de La Cruz. Las fosas están relacionadas con restos de lápidas, y una de ellas está asociada a piezas dentarias humanas.

La arqueóloga considera que los restos de componentes constructivos y óseos explican los cambios del uso del espacio de la misión a lo largo de los años. Interpreta que desde 1657, año del asentamiento de la reducción guaraní en la zona, y durante las primeras décadas del proceso de población, funcionó al menos una iglesia previa. El templo señalado, cercano al cementerio identificado en las excavaciones, fue reemplazado durante 
"La cuestión prioritaria era entonces dotarse de los medios técnicos, legales y conceptuales para proteger el patrimonio...".

el siglo XVIII por uno de mayores dimensiones, que cubrió la superficie del cementerio.

Otra de las intervenciones arqueológicas concretadas por la gestión municipal, especialmente apoyada por la arqueóloga María Eugenia Turus, quien luego de cuatro meses de excavaciones en un terreno privado de la familia Meza halló parte de los muros y solado de los talleres de la reducción. Luego se procedió a resguardar las piezas, finalmente expuestas en el museo para su comunicación. El rescate realizado por el Municipio en la residencia de Meza se concretó gracias al control del municipio en las tareas de construcción que realizaban estos vecinos, y en función de la ordenanza municipal que incluye a todas las propiedades locales en la protección del patrimonio histórico, se realizaron excavaciones arqueológicas.

De la gestión realizada por el municipio y promovida especialmente por la arqueóloga TURUS en la residencia Meza, se rescataron un muro de adobe de 1,10 metro de ancho, solados de piedra y baldosas. Esto correspondería al sitio de los talleres de la reducción, lo que también se denominaba segundo patio.

Luego del registro fotográfico y planimétrico de los hallazgos, se recubrieron para evitar su destrucción. Quedaron localizados en los planos generales del trazado de la reducción jesuítica general que se tiene de la localidad, para, tras acordar con los propietarios del terreno, realizar trabajos de puesta en valor.

La restauración del sillar se realizó por anastilosis, utilizando las mismas piedras y técnicas: barro de unión, acomodando pieza por pieza. Idénticas acciones se llevaron adelante con los hornos de cocción de tejas y ladrillos, que se convierten en recursos de interés turístico, histórico y cultural promovidos por el municipio y la Secretaría de Turismo de la Provincia de Corrientes.

\section{CONCLUSIONES}

Desde los años 80, los arqueólogos, historiadores y especialistas en conservación han reaccionado frente a la erosión de la historia producida por el acelerado fenómeno de crecimiento urbano, particularmente de su subsuelo, en el contexto de estructuras de fundación cada vez más imponentes.

La cuestión prioritaria de dotarse de medios técnicos, legales y conceptuales para proteger el patrimonio se plasmó a nivel internacional en 1992, y a nivel provincial, en el caso de la provincia de Corrientes recién en 2010, con la inclusión de la conservación arqueológica como objetivo del Instituto de Cultura de la Provincia de Corrientes, aunque sin influencia en la normativa municipal.

En la mayoría de los casos correntinos, la cuestión de la valorización de ese patrimonio no se planteó más que en términos de hallazgos, y solo en algunos como el de La Cruz en un verdadero proyecto de arqueología urbana que contribuyó a la conservación del patrimonio urbano, no solo desde el aporte directo para la restauración e intervención urbana, sino también como recurso cultural y turístico.

Durante la puesta en marcha de una obra de intervención, la principal dificultad que vencer reside en el establecimiento de una estrategia para la preservación de los hallazgos, dados los plazos de obra y los recursos necesarios que implican su puesta en valor.

Obstáculo común, a partir de lógicas y prácticas propias de cada disciplina interviniente en el proyecto que frecuentemente persiguen finalidades diversas y no especialmente concordantes, sobre los que el Estado podría intervenir para asegurar su corrección.

Sobrepasar la dificultad de la inclusión de las obras de rescate arqueológico en los planes de interven- 
ción implica un proyecto de accesibilidad que asocia una aproximación transversal e integral a una confrontación de protagonistas, esencial para encontrar puntos de articulación entre cada proceso que respete su autonomía y su rigor.

En la confluencia de estas dos dinámicas, una ligada a una reflexión prolongada en la que se consideran las dimensiones arqueológica y urbana, la otra en la construcción de una verdadera pluridisciplinaridad, reside la originalidad del proyecto arqueológico para la ciudad.

La falta de conciencia colectiva, causal de la distorsión del patrimonio y de la identidad, es una constante amenaza en la gestión de proyectos de arqueología urbana, ya que se prioriza la necesidad de materializar proyectos a corto plazo que continuamente deslegitiman y subestiman el valor de la arqueología urbana como factor necesario para potenciar los recursos culturales.

La arqueología urbana surge del control social sobre los bienes público. Una aproximación de la puesta en valor del patrimonio arqueológico urbano correntino y su gestión desde una concientización que atraviese todos los estratos sociales es fundamental para originar un proyecto urbano que concrete coherentemente un patrimonio urbano y su desarrollo sostenido. 
Patricia Mariño

\section{BIBLIOGRAFÍA}

CÓRDOBA, A. oFM (1934). "La Orden Franciscana en las Repúblicas del Plata". López. Bs. As. pp. 34-35.

COULOMB C. (2012). «L'archéologie urbaine, une science de la ville», La Vie des idées, 10 décembre 2012. ISSN: 2105-3030. URL: http://www. laviedesidees.fr/L-archeologie-urbaine-une-science.html.

GÓMEZ H. "Monumentos y Lugares Históricos de Corrientes". Edición del Gobierno de la Provincia de Corrientes. Corrientes 1942.

GUTIÉRREZ, R. (1969) Iglesias de la Provincia de Corrientes.

(coord. y redactor) (1978) Evolución Urbanística y Arquitectónica del Paraguay. Edit. UNNE. Resistencia.

(1997). "La arquitectura de Buenos Aires en tiempos de Tamburini", en La obra de Francesco Tamburini en Argentina.

GUTIÉRREZ, R. y SÁNCHEZ NEGRETTE, A. (1988). "Evolución Arquitectónica y Urbana de Corrientes". Tomo 1 y 2. Buenos Aires.

GUTIÉRREZ, R., MÉNDEZ, P., KOHAN, M. (2004)ArquitecturasAusentes, obras notables demolidas en la Ciudad de BuenosAires. Cedodal. BuenosAires.

MANTILLA, M. F. (1979) Crónica histórica de la provincia de Corrientes. T 1 y 2. Reedición de la Imprenta de la Provincia de Corrientes.

MARIÑO, M. P. (2006) Fuentes para el análisis sobre las gestiones de intervenciones edilicias en el Convento San Francisco de Asís. Consideraciones sobre los datos del Archivo del Convento San Francisco de Asís de Corrientes. III Simposio de Bibliotecas, Archivos y Museos del Área Franciscana en América. Orden de Frailes Menores. Tarija.

-- (2007) Las actividades agropecuarias en los espacios religiosos. Antiguo sector de quintas del Convento San Antonio de Padua de Corrientes. VIII Congreso de Historia de Corrientes Junta de Historia de la Provincia de Corrientes. Moglia. Corrientes.

MINISTERIO DE CULTURA (2006) Criterios de manejo e intervención en edificios con valor patrimonial. Gobierno de Buenos Aires. Buenos Aires.

- Restauración del Patrimonio del Cementerio de la Recoleta. Intervenciones realizadas 2002-2003. Gobierno de Buenos Aires.

Buenos Aires.

MORENO, C. (1995) De las viejas tapias y ladrillos. ICOMOS- Agencia El Cid- Diario El Viajero- Bs. As. Pp. 95-96.

SCHAVELZON, D. (1992) Túneles y construcciones subterráneas. Arqueología histórica de Buenos Aires. Edit. Corregidor. Buenos Aires.

SCHAVELZON, D. RAMOS, J. (2009) El caserón de Rosas. Corregidor. Buenos Aires. Págs. 15 y 16.

SERRANO, B. (1910). "Guía general de la Pcia. de Corrientes". Imprenta del Gobierno de la Pcia. de Corrientes. Corrientes.

SOLÍS BURGOS, J. A., GARRIDO MESA, J. (2004) Iglesia del Salvador de Sevilla. Cuadernos de obra. Noviembre 04-3. Colegio de Aparejadores y Arquitectos Técnicos de Sevilla. Deleg. Episcopal para la restauración del Salvador. Fundación Aparejadores. Sevilla. Pág. 94 y 95.

TUNA, N. (1999) en «Raport sur la situation de l'archeologie urbaine en Europe». Conseil de l' Europe. P. 219. 